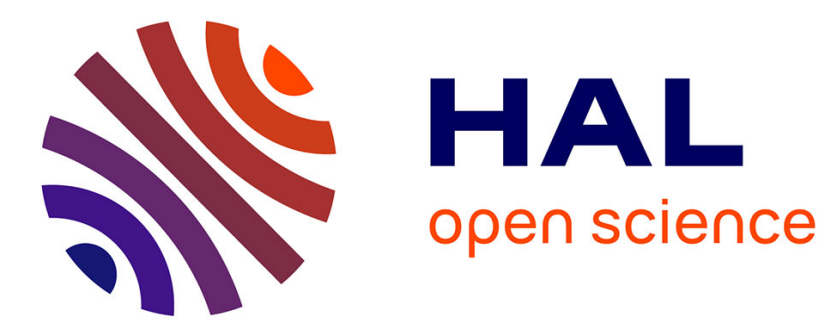

\title{
Self-consistent physical modeling of set/reset operations in unipolar resistive-switching memories
}

Marc Bocquet, Damien Deleruyelle, Christophe Muller, Jean-Michel Portal

\section{To cite this version:}

Marc Bocquet, Damien Deleruyelle, Christophe Muller, Jean-Michel Portal. Self-consistent physical modeling of set/reset operations in unipolar resistive-switching memories. Applied Physics Letters, 2011, 98 (26), 10.1063/1.3605591 . hal-01779321

\section{HAL Id: hal-01779321 \\ https://hal.science/hal-01779321}

Submitted on 26 Apr 2018

HAL is a multi-disciplinary open access archive for the deposit and dissemination of scientific research documents, whether they are published or not. The documents may come from teaching and research institutions in France or abroad, or from public or private research centers.
L'archive ouverte pluridisciplinaire $\mathbf{H A L}$, est destinée au dépôt et à la diffusion de documents scientifiques de niveau recherche, publiés ou non, émanant des établissements d'enseignement et de recherche français ou étrangers, des laboratoires publics ou privés. 


\title{
Self-consistent physical modeling of set/reset operations in unipolar resistive-switching memories
}

\author{
Marc Bocquet, ${ }^{1, \text { a) }}$ Damien Deleruyelle, ${ }^{1}$ Christophe Muller, ${ }^{1}$ and Jean-Michel Portal ${ }^{1}$ \\ IM2NP, UMR CNRS 6242, Aix-Marseille Université, 38 rue Joliot Curie, 13451 Marseille Cedex 20, \\ France
}

(Dated: 4 May 2012)

This letter deals with a self-consistent physical model for set/reset operations involved in unipolar resistive switching memories integrating a transition metal oxide. In this model, set operation is described in terms of a local electrochemical reduction of the oxide leading to the formation of metallic conductive filaments. Beside, reset operation relies on the thermally-assisted destruction of the formed metallic filaments by Joule heating effect. An excellent agreement is demonstrated with numerous published experimental data suggesting that this model can be confidently implemented into circuit simulators for design purpose.

Memory devices based on resistive switching materials are currently pointed out as promising candidates to replace conventional non-volatile memory devices based on charge-storage beyond $2 \mathrm{x}$ nm-technological nodes. ${ }^{1}$ In particular, devices integrating a transition metal oxide (so-called TMO) such as $\mathrm{NiO}, \mathrm{TiO}_{2}, \mathrm{ZnO}$ or $\mathrm{Cu}_{x} \mathrm{O}$, are of growing interest due to their simple Metal/Insulator/Metal (MIM) structure, oxides compatible with complementary metal-oxide-semiconductor technology and low process temperature. ${ }^{2}$ So far, in TMO-based memory devices, the unipolar switching between low resistance state (LRS) and high resistance state (HRS) is explained in terms of creation/destruction of conductive filaments within the oxide. ${ }^{3,4}$ Waser et al. ${ }^{5}$ explained that set, i.e. the transition from HRS to LRS, originates from a local reduction reaction leading to the creation of metallic conductive filaments (CF). During reset, local dissipation of Joule power enhances the thermally activated diffusion of defects and/or of different atomic species constituting the $\mathrm{CF}$ combined with a local oxidation process. ${ }^{6,7}$ Based on this phenomenological description, several models for reset were reported in Refs. 8-10 but very few offer a model for set. ${ }^{11}$ Furthermore, it has to be stressed that there is currently no complete model taking into account both set and reset operations that could be easily implemented in circuit simulators for design purpose.

In this context, this paper proposes a self-consistent physical model accounting for both set/reset operations in NiO-based unipolar resistive switching devices. After uncovering the theoretical background and the set of relevant physical parameters, the model is confronted to quasi-static and dynamic experimental data from literature.

FIG. 1 schematically describes the set/reset mechanisms controlling the resistive switching phenomenon. Set (resp. reset) is assumed to be due to the creation (resp. destruction) of CF between two electrochemically inert electrodes. Starting from LRS, the existing CF may

\footnotetext{
a)Electronic mail: marc.bocquet@im2np.fr
}

be heated by Joule effect thanks to the application of an electric field $\xi$, as reported in Ref. 12. CF top and bottom boundaries are kept at thermal equilibrium with connected electrodes at room temperature $\left(T_{a m b}\right)$ whereas the sidewalls are expected to exchange heat flow with the surrounding oxide. Thus, in one dimension geometry the heat equation can be simply written as:

$$
\sigma_{C F}(x) \cdot \xi(x)^{2}=-K_{t h_{C F}} \frac{\partial^{2} T_{C F}(x)}{\partial x^{2}}+h \frac{T_{C F}(x)-T_{O x}}{t_{O x}}
$$

where $\sigma_{C F}$ is the CF conductivity, $T_{C F}(x)$ the CF temperature, $T_{O x}$ the oxide temperature, $K_{t h_{C F}}$ the CF thermal conductivity, $t_{O x}$ the oxide thickness and $h$ the heat transfer coefficient between $\mathrm{CF}$ and surrounding oxide.

In LRS CF is assumed to be metallic with a high conductivity $\sigma_{C F}$. In contrast, when $\mathrm{CF}$ is dissolved, the resistance of MIM structure is controlled by the resulting oxide gap separating the two CF fragments ( $c f$. FIG. 1). As a consequence, a lower conductivity noted $\sigma_{O x}$ accounts for the electronic transport in HRS. Assuming the current conservation through the whole structure, an analytical expression of the electric field $\xi$ can be derived $(\nabla J=0)$ :

$$
\xi(x)=I_{0} \cdot R(x)
$$

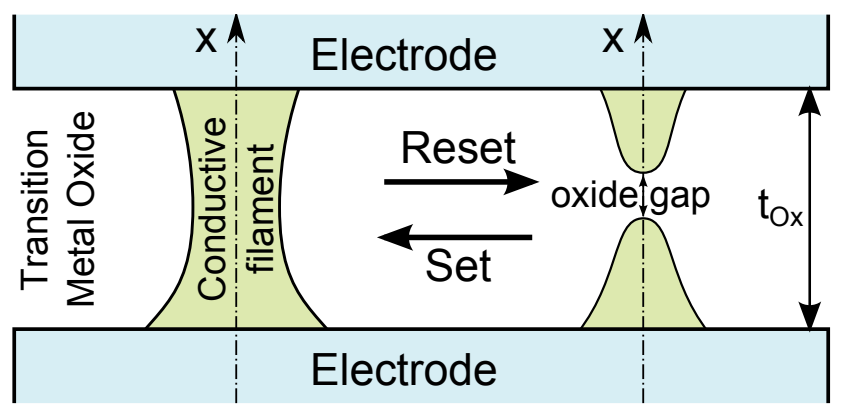

FIG. 1. Schematic representation of a formed and dissolved conductive filament resulting from set and reset operations respectively in MIM structure. During reset, the inner temperature is raised by Joule effect and leads to the destruction of the CF. In contrast, during set a electrochemical local reduction process enables restoring CF. 
where the resistance per unit length $R(x)$ is

$$
\begin{gathered}
R(x)=\frac{1}{r_{C F}^{2}(x) \pi\left(\sigma_{C F}(x)-\sigma_{O x}\right)+r_{C F_{\max }}^{2} \pi \sigma_{O x}} \\
I_{0}=\frac{V_{C e l l}}{\int_{0}^{t_{O x}} R(x) d x}
\end{gathered}
$$

$I_{0}$ is the ohmic current in the MIM structure, $V_{C e l l}$ the applied voltage, $r_{C F}(x)$ and $r_{C F_{\max }}$ denote respectively the radius and the maximal radius of the $\mathrm{CF}$ in cylindrical geometry.

Two distinct mechanisms were considered to describe the creation and the destruction of $\mathrm{CF}$ : a local redox process $^{5,13}$ and a thermally-assisted diffusion ${ }^{8}$. One can consider a classical redox equations such as:

$$
\mathrm{Ni}^{2+}+2 \cdot e^{-\underset{\text { red }}{\stackrel{o x}{\leftrightarrows}}} \mathrm{Ni}
$$

in which the reaction velocities for both reduction and oxidation processes may be expressed classically by the Butler-Volmer equation: ${ }^{14}$

$$
\begin{gathered}
\nu_{r e d}=k_{0} e^{-\frac{\Delta r G_{0}+2(1-\alpha) F\left(E-E_{e q}\right)}{R \cdot T_{o x}}}\left(1-C_{N i}\right) \\
\nu_{o x}=k_{0} e^{-\frac{\Delta r G_{0}-2 \alpha F\left(E-E_{e q}\right)}{R \cdot T_{C F}(x)}} C_{N i}
\end{gathered}
$$

$\alpha$ is the asymmetry factor, $k_{0}$ kinetics constant of electrochemical reaction, $R$ is the ideal gas constant, $F$ is the Faraday constant, $\Delta r G_{0}$ is the free energy of the reaction at equilibrium and finally $E_{e q}$ is the equilibrium potential. Moreover $C_{N i}$ denotes the dimensionless concentration of metallic species. To determine the potential of the reduced and oxidized species such as $\mathrm{Ni}$ and $\mathrm{Ni}^{2+}$ respectively, the mechanism is supposed to be isotropic and the redox potential $E$ is assumed to be equal to $-\left|V_{C e l l}\right|$.

Finally, in order to properly account for the metallic nature of the $\mathrm{CF}$, its conductivity relies on a temperature coefficient $\alpha_{T}$ as described by Russo et al. ${ }^{12}$ where $\sigma_{C F_{0}}$ is the CF conductivity at room temperature $\left(T_{a m b}\right)$ :

$$
\sigma_{C F}(x)=\frac{\sigma_{C F_{0}}}{1+\alpha_{T} \cdot\left(T_{C F}(x)-T_{a m b}\right)}
$$

As already proposed by Russo et al. ${ }^{8}$, the thermal rupture of $\mathrm{CF}$ in reset operation can be described by a local diffusion velocity $\left(\nu_{\text {diff }}\right)$ of the metallic species:

$$
\nu_{d i f f}=k_{d i f f} \cdot e^{-\frac{E_{a}}{k_{b} \cdot T_{C F}(x)}} \cdot C_{N i}
$$

where $E_{a}$ is the activation energy governing the thermally-assisted exodiffusion of metallic species.

Regarding Eq.5, we assumed that electron density available during set could not limit the reduction process. Indeed, during set the growth of the CF is initiated
TABLE I. Physical parameters used for simulations

\begin{tabular}{ll}
\hline \hline$k_{\text {diff }}=5 \times 10^{10} \mathrm{~s}^{-1}$ & $E_{a}=1.9 \mathrm{eV}$ \\
\hline$k_{0}=10^{12} \mathrm{~s}^{-1}$ & $r_{C F_{\max }}=60 \mathrm{~nm}$ \\
\hline$\alpha_{T}=1.1 \times 10^{-3} \mathrm{~K}^{-1}$ & $h=100 \mathrm{~W} /\left(\mathrm{K} \cdot \mathrm{m}^{2}\right)$ \\
\hline$T_{O x}=T_{a m b}$ & $K_{t h}=91 \mathrm{~W} /(\mathrm{K} \cdot \mathrm{m}) \mathrm{ref} .7$ \\
\hline$\alpha=0.5$ & $\sigma_{O x}=12.5 \mathrm{k}^{-1} \mathrm{~cm}^{-1} \mathrm{ref} .8$ \\
\hline$\Delta r G_{0}-2(1-\alpha) \mathrm{F} \cdot E_{e q}=222 \mathrm{~kJ} \cdot \mathrm{mol}^{-1}$ \\
\hline$\sigma_{C F_{0}}=6.67 \mathrm{~m}^{-1} \mathrm{~cm}^{-1}$ ref.8, 9, and 16 \\
\hline$t_{O x}=160 \mathrm{~nm}$ for ref. 11 or $t_{O x}=30 \mathrm{~nm}$ for ref. 15 \\
\hline
\end{tabular}

at the cathode side. As the CF grows toward the anode, it is assumed to act as "virtual cathode" 5 allowing electrons to flow freely from the real cathode toward the reduction site.

Finally, the description of set and reset mechanisms enables proposing a self-consistent master equation relying on a chemical kinetics:

$$
\frac{d C_{N i}}{d t}=\nu_{r e d}-\nu_{o x}-\nu_{d i f f}
$$

$\mathrm{CF}$ radius $\left(r_{C F}=r_{C F_{\max }} \times C_{N i}\right)$ is calculated from the electric field (Eq. 2), the CF temperature (Eq. 1), the diffusion and reaction velocities (Eqs. 6, 7\&9,) and finally from the concentration of metallic species (Eq. 10). It is has to be mentioned that considering energies involved in Eq. 7\&9, the CF destruction is mainly governed by the diffusion process rather than oxidation.

To validate the proposed theoritical approach, the model was confronted to quasi-static and dynamic experimental data from the literature. FIG. 2(a) and 2(b) show quasi-static set and reset $I(V)$ characteristics mea- (a)

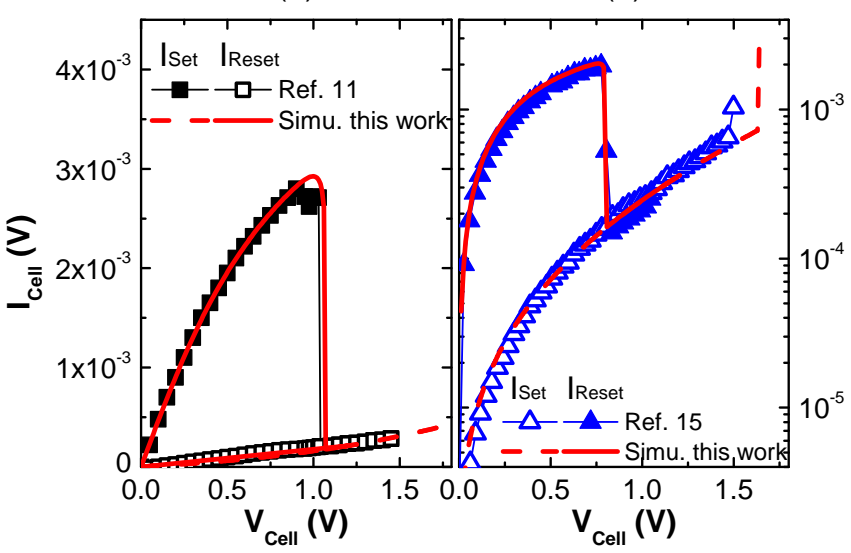

FIG. 2. Experimental $I(V)$ characteristics measured on a $\mathrm{NiO}$-based memory structure presented in (a) ref.11 and (b) ref.15 and the corresponding simulation by using the present model and the physical parameters given in Table I. The CF profile obtained after the set operation is used as the initial state to simulate the subsequent reset operation. 
sured on NiO-based memory elements by Cagli et al. ${ }^{11}$ and Lee et al. ${ }^{15}$ In both studies, memory elements consisted in $\mathrm{Pt} / \mathrm{NiO} / \mathrm{Pt}$ stack with respective nickel oxide thicknesses of $160 \mathrm{~nm}^{11}$ and $30 \mathrm{~nm} .{ }^{15}$ Using the set of physical parameters given in Table I together with the actual nickel oxide thickness, the present model shows an excellent agreement with experimental data for both set and reset operations. Moreover, it must be underlined that the model is used continuously since it relies on a self-consistent kinetics equation accounting for both $\mathrm{CF}$ creation and destruction mechanisms. This numerical feature is a key point for a model dedicated to an implementation in computer-aided design tools. From a practical point of view, the CF profile obtained after the set operation is used as the initial state to simulate the subsequent reset operation.

FIG. 3(a\&b) shows that the proposed model satisfactorily matches the experimental increase of set and reset voltages along with the programming ramp speed reported by Cagli et al.. ${ }^{11}$ The increase of reset voltage may be interpreted in terms of competition between creation and destruction mechanisms. Indeed, as ramp speed increases, a larger current (i.e. a larger applied voltage) is necessary to achieve reset in a shorter time. Through Eq. 6, a larger applied voltage implies a strengthening of the reduction process that limits the filament destruction. Finally, the turn back of the structure toward HRS is achieved thanks to an increase of $V_{\text {reset }}$. Beside, the closing of the gap between $V_{\text {set }}$ and $V_{\text {reset }}$ at highest sweep rates may lead to some reset/set instabilities as proposed in Ref. 17.

A reported in numerous works, the resistance in LRS (noted $R_{L R S}$ ) and reset current strongly depend on the maximum current reached during the preceding set operation ${ }^{18-21}$ (referred as $I_{\text {SetMax }}$ ). This feature can be understood in terms of reduction of $\mathrm{CF}$ radius that concomitantly increases the resistance of the

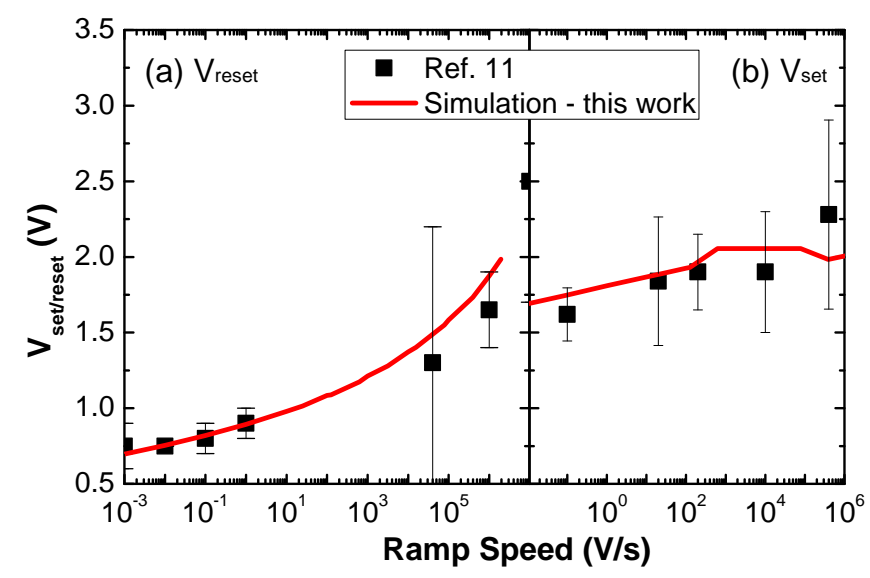

FIG. 3. (a) Set and (b) reset voltages as a function of the programming ramp speed based on the experimental results reported in Ref. 11 The calculated curves were obtained for the physical parameters given in Table I.

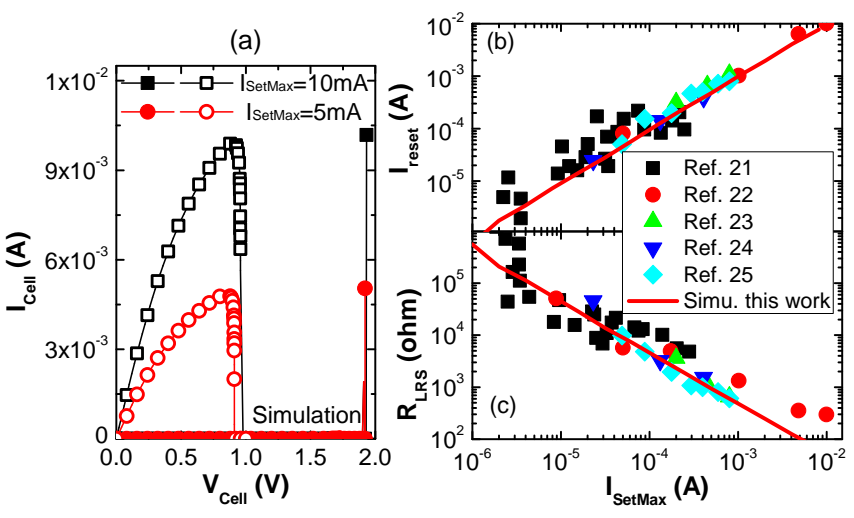

FIG. 4. (a) Simulation of set and reset $I(V)$ characteristics for $I_{\text {SetMax }}=5 \mathrm{~mA}$ and $10 \mathrm{~mA}$. (b) Maximum current during the reset operation ( $I_{\text {Reset }}$ ) and (c) the resistance in LRS as a function of the maximum current during the preceding set operation $\left(I_{\text {SetMax }}\right)$. Experimental data were extracted from Ref. 21-25. The parameters of the Table I were used for simulations.

MIM structure. ${ }^{21}$ FiG. 4(a) reports the simulated set and reset $I(V)$ characteristics for two different maximum currents $I_{\text {SetMax }}$. As expected, a decrease of the reset current is observed together with an increase of $R_{L R S}$. FIG. 4(b) and 4(c) show the experimental evolutions of $I_{\text {reset }}$ and $R_{L R S}$ as a function of the maximum set current $I_{\text {SetMax }} \cdot{ }^{21}$ The proposed model matches well the experimental data obtained by various authors and confirms the scalability of the reset current $I_{\text {reset }}$ in NiO-based resistive memories. The reset current may be scaled down by limiting the maximum set current through an integrated select device (e.g. transistor or load resistor) in series with memory element. Finally, it has to be mentioned that the present model may also be used to simulate retention properties. Nevertheless, a complete set of experimental retention data is required to calibrate the model. This work is under way.

In conclusion, this letter deals with a self-consistent physical model well suited for describing simultaneously set and reset operations in unipolar resistive switching memories based on transition metal oxide. By gathering local electrochemical reactions and a thermal diffusion mechanism in a single master equation, the model enables accounting for both creation and destruction of conductive filaments. The simulation results satisfactorily match numerous quasi-static and dynamic experimental data published in literature on resistive switching devices. Beside, the model can be easily implemented in circuit simulators and enables predicting relevant trends required for designing innovative architectures such as memory matrix, distributed memories or Field-Programmable Gate Array.

Authors would like to thank Prof. Daniele Ielmini (Politecnico di Milano), Dr. Robert Müller (IMEC) and Dr. Renaud Bouchet (LCP) for fruitful discussions. 
${ }^{1} \mathrm{~S}$. Hong, in Proc. IEEE Int. Electron Devices Meeting (IEDM) (2010) pp. 292-295.

${ }^{2}$ Y. S. Chen, H. Y. Lee, P. S. Chen, P. Y. Gu, C. W. Chen, W. P. Lin, W. H. Liu, Y. Y. Hsu, S. S. Sheu, P. C. Chiang, W. S. Chen, F. T. Chen, C. H. Lien, and M.-J. Tsai, in Proc. IEEE Int. Electron Devices Meeting (IEDM) (2009) pp. 1-4.

${ }^{3}$ G.-S. Park, X.-S. Li, D.-C. Kim, R.-J. Jung, M.-J. Lee, and S. Seo, Appl. Phys. Lett. 91, 222103 (2007).

${ }^{4}$ D. Deleruyelle, C. Dumas, M. Carmona, C. Muller, S. Spiga, and M. Fanciulli, Applied Physics Express 4, 051101 (2011).

${ }^{5}$ R. Waser, R. Dittmann, G. Staikov, and K. Szot, Advanced Materials 21, 2632 (2009).

${ }^{6}$ U. Russo, D. Ielmini, C. Cagli, and A. L. Lacaita, Transaction on Electron Devices 56, 186 (2009).

${ }^{7}$ S. H. Chang, S. C. Chae, S. B. Lee, C. Liu, T. W. Noh, J. S. Lee, B. Kahng, J. H. Jang, M. Y. Kim, D.-W. Kim, and C. U. Jung, Appl. Phys. Lett. 92, 183507 (2008).

${ }^{8}$ U. Russo, D. Ielmini, C. Cagli, and A. L. Lacaita, Transaction on Electron Devices 56, 193 (2009).

${ }^{9}$ Y. Sato, K. Kinoshita, M. Aoki, and Y. Sugiyama, Applied Physics Letters 90, 033503 (2007).

${ }^{10}$ S. B. Lee, S. C. Chae, S. H. Chang, and T. W. Noh, Appl. Phys. Lett. 94, 173504 (2009).

${ }^{11}$ C. Cagli, D. Ielmini, F. Nardi, and A. L. Lacaita, in Proc. IEEE Int. Electron Devices Meeting IEDM 2008 (2008) pp. 1-4.

${ }^{12}$ U. Russo, D. Ielmini, C. Cagli, A. L. Lacaita, S. Spiga, C. Wiemer, M. Perego, and M. Fanciulli, in Proc. IEEE Int. Electron Devices Meeting IEDM 2007 (2007) pp. 775-778.

${ }^{13}$ F. Pan and V. Subramanian, in Proc. Int Simulation of Semiconductor Processes and Devices (SISPAD) Conf (2010) pp. 19-22.

${ }^{14}$ A. J. Bard and L. R. Faulkner, Electrochemical Methods: Fundamentals and Applications, edited by J. Wiley and S. Inc. (New York, January 2001).

${ }^{15}$ M.-J. Lee, Y. Park, B.-S. Kang, S.-E. Ahn, C. Lee, K. Kim,
W. Xianyu, G. Stefanovich, J.-H. Lee, S.-J. Chung, Y.-H. Kim, C.-S. Lee, J.-B. Park, and I.-K. Yoo, in Proc. IEEE Int. Electron Devices Meeting IEDM 2007 (2007) pp. 771-774.

${ }^{16} \mathrm{~T}$. Ohgai, L. Gravier, X. Hoffer, M. Lindeberg, K. Hjort, R. Spohr, and J.-P. Ansermet, J. Phys. D Appl. Phys. 36, 3109 (2003).

${ }^{17}$ D. Ielmini, Electron Device Letter 31, 552 (2010).

${ }^{18}$ D. C. Kim, S. Seo, S. E. Ahn, D.-S. Suh, M. J. Lee, B.-H. Park, I. K. Yoo, I. G. Baek, H.-J. Kim, E. K. Yim, J. E. Lee, S. O. Park, H. S. Kim, U.-I. Chung, J. T. Moon, and B. I. Ryu, Appl. Phys. Lett. 88, 202102 (2006).

${ }^{19}$ K. Kinoshita, K. Tsunoda, Y. Sato, H. Noshiro, Y. Yamazaki, T. Fukano, S. Yagaki, M. Aoki, and Y. Sugiyama, in Proc. 22nd IEEE Non-Volatile Semiconductor Memory Workshop (2007) pp. 66-67.

${ }^{20}$ S. B. Lee, S. C. Chae, S. H. Chang, J. S. Lee, S. Seo, B. Kahng, and T. W. Noh, Appl. Phys. Lett. 93, 212105 (2008).

${ }^{21}$ F. Nardi, D. Ielmini, C. Cagli, S. Spiga, M. Fanciulli, L. Goux, and D. Wouters, Solid-State Electronics 58, 42 (2011).

${ }^{22}$ S. Seo, M. J. Lee, D. H. Seo, E. J. Jeoung, D.-S. Suh, Y. S. Joung, I. K. Yoo, I. R. Hwang, S. H. Kim, I. S. Byun, J.-S. Kim, J. S. Choi, and B. H. Park, Appl. Phys. Lett. 85, 5655 (2004).

${ }^{23}$ K. Kinoshita, K. Tsunoda, Y. Sato, H. Noshiro, S. Yagaki, M. Aoki, and Y. Sugiyama, Appl. Phys. Lett. 93, 033506 (2008).

${ }^{24}$ T.-N. Fang, S. Kaza, S. Haddad, A. Chen, Y.-C. Wu, Z. Lan, S. Avanzino, D. Liao, C. Gopalan, S. Choi, S. Mahdavi, M. Buynoski, Y. Lin, C. Marrian, C. Bill, M. VanBuskirk, and M. Taguchi, in Proc. Int. Electron Devices Meeting IEDM '06 (2006) pp. 1-4.

${ }^{25}$ K. Tsunoda, K. Kinoshita, H. Noshiro, Y. Yamazaki, T. Iizuka, Y. Ito, A. Takahashi, A. Okano, Y. Sato, T. Fukano, M. Aoki, and Y. Sugiyama, in Proc. IEEE Int. Electron Devices Meeting IEDM 2007 (2007) pp. 767-770. 